\title{
Habitantes de los bordes
}

Lo primero que conocí de Anne Carson fue su cara pálida, surcada de arrugas en blanco y negro, recortada contra un fondo radiante, salpicado apenas por puntos que podían ser gente, y bordeado de sombras que podían ser árboles. La fotografía ilustraba un artículo que anunciaba la publicación de Nox y recorría algunas claves de la poética de Carson $^{1}$. Entre ellas, la presencia del deseo, la triangulación constante -lo que ella llama "a third angle of vision". Y, también, la traducción. "Translation, the act of renaming, is clearly crucial to Carson's method of coming to grips with loss", dice en un momento el artículo, como si dijera que Carson, quien ha enseñado y traducido a los clásicos griegos y del latín, es también una traductora de su propia historia, sus lecturas, pensamientos, dolores y demases. Que los poemas, la prosa que se rompe en las páginas que escribe fueran, también, de algún modo, traducción. Comencé de inmediato a leer a Carson mientras que como inmigrante recién estrenada lidiaba con mis propias pérdidas y con el encuentro de una lengua que no dominaba del todo. Unos años después, mientras cursaba mi doctorado en literatura y cultura latinoamericana, comencé a traducir The Glass Essay de Carson. Sin mayor preparación y sin otro motivo aparente que el deseo de acercarme aún más a esa escritura, a esa voz y sus derroteros, como si quisiera leer de una manera más honda, como poniendo un texto bajo la piel. Cuando la traducción estuvo lista me pareció lógico compartirla, publicarla y me aboqué a eso. El libro se editó en Chile, el segundo de Carson que circulaba allá. No recibí dinero por la traducción, pero fui feliz. De pronto, me había vuelto traductora y amateur. Una entre tantas y tantos.

En 2016 Deborah Smith ganó junto a la autora coreana Hang Kang el Man Booker International Prize por The Vegetarian. Por primera vez el premio se entregaba a un autor de una obra de ficción específica y, por primera vez también, se repartía entre una autora y su traductora al inglés ${ }^{2}$. Smith y Hang Kang se llevaban cada una 25 mil dólares y con eso Smith hacía historia, una marginal, como la traducción misma, que ocupa en el imaginario general el lugar de equilibrista en los bordes del mundo literario ${ }^{3}$. Con la precariedad del equilibrista

1 “The Unfolding”, de Meghan O'Rourke fue publicado en The New Yorker en 2010.

2 Entre 2005 y 2015 el premio se entregó cada dos años a un autor o una autora por toda su obra publicada -escrita en inglés o mayormente traducida a esta lengua-, un reconocimiento a la trayectoria.

3 Se ha criticado la traducción de Smith por tomar 'demasiadas libertades' con el original. La idea de la libertad para con el original es una que exploraremos en este libro. Sobre el caso específico de Smith ver, por ejemplo, Armitstead (2018) y Fan (2018).

Ә Open Access. (C) 2021 Soledad Marambio, published by De Gruyter. (c) BY-NC-ND This work is licensed under the Creative Commons Attribution-NonCommercial-NoDerivatives 4.0 International License. https://doi.org/10.1515/9783110749984-001 
en mente, Smith, saludó al premio como un gran reconocimiento y como un cambio enorme en la vida de los traductores premiados. Lo del cambio enorme se refería específicamente al hecho de recibir dinero -y tanto dinero- por el trabajo de traductora, ya que en el Reino Unido los traductores literarios reciben por hora bastante menos que el sueldo mínimo ${ }^{4}$. La realidad en otras partes del mundo no es mejor. Por ejemplo, detengámonos un segundo en Megan McDowell, traductora estadounidense quien a comienzos de 2017 fue finalista del Man Booker International Prize junto a Samantha Schweblin, y quien se ha convertido en una de las traductoras del español, sobre todo de literatura latinoamericana, más prolíficas y visibles de los últimos años. McDowell vive desde hace unos años en Chile y por mucho tiempo se pasó la mayor parte de sus días traduciendo para un banco de inversiones para poder traducir literatura durante las noches, o cuando pudiera. Dos trabajos entonces, uno para la subsistencia, y el otro, ¿para qué? Un artículo sobre McDowell publicado en LitHub recoge esa misma pregunta ${ }^{5}$ :

As a freelance literary translator -and there's no other kind- McDowell's catalog demonstrates her power as a curative force, as well as the precarious nature of her work. Of her last eight books, each one has been published with a different press, and you can find McDowell's name on only two of those covers. Even when she's working with great writers and great presses, the compensation is minimal- in some cases close to nonexistent... "I'm not a translator for the fame or the money." She hesitates. "I guess then the question is why am I a translator?”. (el énfasis es mío, MacNamara 2017)

Esa misma pregunta recorre todo este libro, ¿por qué un traductor traduce? Y esa pregunta arrastra consigo a otras: ¿Quién es, entonces, un traductor? ¿Por qué trabaja sin pensar en la recompensa? ¿Por qué se prepara, se entrega, se absorbe en una actividad que no le dejará ni reconocimiento ni dinero? Podemos anticipar que habrá muchas respuestas para tantas preguntas. Una podría ser que se traduce para compartir la belleza de lo leído en otra lengua, como dijo la traductora Lina Protopapa en un artículo, el mismo donde Jennifer Croft explicó que para ella la traducción era una gran manera de dar prioridad a las voces marginadas de autoras mujeres y donde Marilyn Booth contó que había comenzado a traducir motivada por la frustración que le producía la falta de circulación en inglés de la obra de mujeres árabes ${ }^{6}$. Frustraciones, luchas, compartir belleza. En el fondo de esas respuestas, deseo, deseo, deseo: de dar voz, de diseminar algo que se piensa vale la pena. La pregunta por el deseo del tra-

4 Ver Smith (2017).

5 McDowell dejó hace poco el trabajo en el banco y declaró "I'm poorer but more-well rested". Ver (“Ac·Cent·Tchu·Ate the Intertextuality: Interview!” 2019).

6 Ver Goyal (2019). 
ductor también recorre estas páginas y también la pregunta sobre cómo ese deseo se relaciona con el material de la traducción, con el diálogo que se establece a través de ella, con la precariedad de la labor, con la independencia del traductor que se sitúa al margen de instituciones y su importancia para el mercado literario y para el campo cultural. McDowell es un ejemplo de la traductora como curadora de trabajos que de otra manera no llegarían a tierras extranjeras, trabajadora creativa que no recibe paga por interpretar textos, por llevarlos, así, interpretados, de una lengua a otra, convertidos en libros, bienes culturales que se transan en el mercado. ¿Qué clase de trabajo es ese que produce bienes, pero no remuneración? Es el trabajo de un amateur, de alguien que ama, si nos atenemos a la raíz etimológica de la palabra y si dejamos de lado la carga negativa que el término "amateur" ha ido adquiriendo con el paso del tiempo desde sus primeros usos en el siglo XVIII hasta la actualidad.

Uno de los propósitos de este libro es sumarse al trabajo de rescate de la figura del amateur, hacer su elogio -en este caso desde el campo de la traducción- y ponderar su libertad de movimiento, su pasión, su preparación, pero también reflexionar sobre la precariedad de su condición, siempre marginal. Recientemente algunos intelectuales y académicos han propuesto una mirada que salva al amateur de las apreciaciones peyorativas que lo presentan como un sujeto poco preparado, poco hábil y que no toma con seriedad su afición. En ese sentido, mi estudio se suma al trabajo reciente de intelectuales como Bernard Stiegler, Paloma Duong, Saikat Majumdar, Marjorie Garber y al hecho en los años 70 por Robert Stebbins. Si hablo de amateurs cuando hablo de traductores es porque propongo como uno de los argumentos centrales de este estudio la idea de que todo traductor literario es un amateur (y no solo un trabajador freelance como decía más arriba MacNamara), es decir, alguien que destina sus recursos y su tiempo libre -el no dedicado a un trabajo remunerado- a otro trabajo del que no depende su subsistencia y al que se encuentra ligado por el deseo, el amor. Es ese deseo el que lo impulsa, el que pone en movimiento el proceso que lleva a la traducción y es ese mismo deseo el que lo mantiene en movimiento a pesar de la precariedad económica del trabajo. Es, entonces, el deseo de la traductora, del traductor, el que pone en movimiento ciertos materiales, bienes culturales, que de otro modo no tendrían la posibilidad de un recorrido. Por todo esto, nos preguntaremos a lo largo del libro quién es un traductor, por qué traduce, y también nos preguntaremos qué es lo que desea o que está detrás de su deseo. Además, exploraremos su contexto porque un traductor es un agente cultural que crea trayectorias -de bienes, de relaciones intelectuales, culturales, lingüísticas- que no se dan en el vacío sino dentro de ciertos contextos históricos, políticos, económicos y culturales y en un territorio que, por definición, cubre distintos países, lenguas y culturas. 
En este trabajo, mi mirada se detiene en un escenario de traducción específico, el del principio de la relación traductora entre Estados Unidos y Latinoamérica a comienzos del siglo XX, y es desde allí que planteo, una vez más, las preguntas que hasta hoy se hacen los traductores como McDowell, Smith y tantos otros. Tal como hace Sherry Simon en su trabajo sobre ciudades construidas en torno a la traducción, busco en una narrativa que se desenvuelve en un escenario específico el porqué de esta, ya que como dice Naoimi Seidman, la traducción "cannot be separated from the material, political, cultural or historical circumstances of its production ... in fact represents an unfolding of these conditions" (Simon 2013: 8). Además de este escenario de traducción puntual, para explorar los porqués de la traducción y el rol del amateurismo en su práctica, he elegido seguir las trayectorias y el trabajo de dos traductores estadounidenses, Alice Stone Blackwell e Isaac Goldberg. Sin actores específicos es muy difícil analizar el escenario de traducción que aquí me ocupa y como este libro es, sobre todo, una exploración sobre la naturaleza del traductor, me detengo en estos dos traductores que estuvieron entre los primeros en traducir literatura latinoamericana para audiencias estadounidenses. Luego de presentarlos, de empezar a conocerlos, volveré al escenario -al tiempo y el lugar y a las condiciones culturales y políticas- que recorre este libro para entender por dónde nos moveremos en las páginas que siguen.

Blackwell (Orange, NJ 1857-Cambridge, MA 1950) fue sufragista, editora del Woman's Journal por más de tres décadas, y, antes de concentrarse en el español, reconocida traductora al inglés del ruso, ídish y armenio. A pesar de que no hablaba ni leía en ninguno de estos últimos idiomas, Blackwell, graduada del Boston College, produjo antologías poéticas o libros de poesía en cada uno de ellos, motivada por sus simpatías políticas y humanitarias. Su método consistía en pedirles a nativos en la lengua a traducir que hicieran una primera versión en inglés de los textos, sobre la cual ella versificaba. Con el español, sin embargo, siguió un camino distinto y después de versificar sobre algunas traducciones de otros, decidió aprender el idioma. Para su formación autodidacta se valió de leer enormes cantidades de poesía con la ayuda de un diccionario, así traducía los poemas que más le gustaban y convirtió su práctica en aprendizaje. Según decía, trabajaba en sus traducciones por placer y solo en los momentos libres de su "very busy life", es decir, una amateur en todo el sentido de la palabra si pensamos en los orígenes de esta misma. A lo largo de tres décadas, Blackwell acumuló una enorme cantidad de material que reunido dio forma a su extensa colección de poesía latinoamericana traducida al inglés, su Some Spanish-American Poets, publicada en 1929 y reeditada cinco veces desde entonces.

Goldberg (Boston, MA 1887-Brookline, MA 1938) también se movía entre varias lenguas. Aprendió ídish en casa y español, francés, portugués, italiano y otros idiomas en la universidad, porque a diferencia de Blackwell, Goldberg, quien obtuvo 
un doctorado en lenguas romances en Harvard en 1912, se formó como profesional de las letras. Sin embargo, al igual que Blackwell, circulaba por fuera de la academia. En cuanto terminó sus estudios, Goldberg se dio cuenta de que no estaba hecho para ser profesor y durante la Primera Guerra comenzó a escribir artículos sobre literatura latinoamericana, teatro y música. Poco después empezó su carrera de traductor -que fue intensa, prolífica, breve-, intentando ganarse la vida con la práctica, volverla profesión. Entre los libros que produjo en ese tiempo se destacan Brazilian Tales (1921) y un estudio sobre los modernistas latinoamericanos llamado Studies in Spanish-American Literature (1920). Blackwell y Goldberg pertenecían a la intelectualidad bostoniana y los dos tenían conexiones con el departamento de lenguas romances de Harvard, fuertemente vinculado con las ideas del panamericanismo, el movimiento que les serviría como telón de fondo y que influiría de manera directa en sus prácticas de traducción y en sus modos de acercarse a Latinoamérica, su gente, su literatura.

Los años del panamericanismo definen, entonces, el marco histórico en el que se desarrolla el trabajo de Blackwell y Goldberg. Definir a su vez el panamericanismo es un asunto complejo porque su naturaleza es "esquiva” como dice David Sheinin, quien lo explica de la siguiente manera:

At its simplest (Pan Americanism) defines a movement started in the 1880s by diplomats, business leaders and politicians from many countries. Spearheaded principally by the United States, Pan Americanism was meant to organize the Western Hemispheric republics into an international cooperative body (Sheinin 2000: 1).

Así mismo lo resumen otros, como Mark T. Berger o Ricardo Salvatore, para luego, invariablemente, mencionar su doblez, lo que se esconde detrás de esa proclamada idea de cooperación internacional ${ }^{7}$. Para poner este doblez en las palabras de Sheinin: "Pan Americanism has always been U.S. led, the friendly face of U.S. dominance in the hemisphere" (Sheinin 2000: 1). Esta idea de dominación, el intento de Estados Unidos por instalar su liderazgo y su hegemonía económica y política en la región, se va a reflejar inequívocamente en el escenario de traducción que exploro aquí. La propuesta del panamericanismo creó la necesidad de saber más sobre Latinoamérica, sobre sus habitantes, culturas e historias. Lo que se conocía sobre la región para fines del siglo XIX y comienzos del XX era poco, vago, insuficiente para ser la base desde la que se construyera un organismo de cooperación regional. Por lo mismo, pronto la necesidad de saber más llevó a los actores políticos y económicos del panamericanismo a aliarse con ciertos miembros de la academia estadounidense embarcados en la recolección de conocimiento sobre la región. Como señala Ricardo Salvatore,

7 Ver Berger (1995) y Salvatore (2016). 
"enhanced knowledge, the argument ran, would generate greater mutual trust in Inter-American Relations" (Salvatore 2016: 1). Es en este entorno de búsqueda de conocimiento que Blackwell y Goldberg intentaban acercar la literatura latinoamericana a los lectores de Estados Unidos. Como veremos, estos traductores se relacionaron de maneras distintas con el panamericanismo y sus propuestas, resistiendo, anotando, corrigiendo o colaborando, pero siempre articulando su ser traductor en relación a los marcos establecidos por el proyecto panamericano. Explorando estas formas de relacionarse con él, ahondaremos en otro punto central de esta investigación: ver de qué manera la naturaleza amateur de la traducción literaria entra en tensión con proyectos hegemónicos como el panamericanismo y cómo en esas tensiones se van iluminando ciertas características esenciales de la práctica.

\section{Sobre los nombres}

Los márgenes por los que circula una traductora o un traductor van más allá de los planteados en esta discusión específica sobre el panamericanismo. Los bordes sobre los que hace equilibrio la traducción son múltiples. La traductora se encuentra en los márgenes del campo literario, a la sombra del autor, muchas veces fuera de las tapas de los libros y apenas remunerada por su trabajo, es decir, también, en los bordes del sistema de producción capitalista en el que nos movemos. En 2019, Matthew Reynolds, profesor de la Universidad de Oxford, presentó un enorme proyecto colaborativo de traducción llamado Prismatic Jane Eyre. El proyecto explora la relación entre Jane Eyre, la novela de Charlotte Brönte publicada en 1847, y sus cientos de traducciones producidas y publicadas en el mundo en los casi dos siglos que han transcurrido desde su aparición ${ }^{8}$. Es decir, entre Jane Eyre y las cientos de Jane Eyre que han recorrido el mundo, desde Chile hasta China, pasando por casi todos los rincones del mapa. Uno de los objetivos de este proyecto es resaltar la figura del traductor, buscarla, encontrarla, sacarla a la luz, pero los investigadores se han topado con el problema de la desaparición del traductor, en este caso, con la de muchos de los cientos de traductores de la novela de Brönte. Reynolds explica que en gran parte de las 594 traducciones de Jane Eyre que han conseguido rastrear, "usually all that is known of a

8 Ver Chau (2020) y el sitio web del proyecto Prismatic Jane Eyre, que culminará con un libro con los resultados de la investigación que involucra a decenas de académicos y traductores. El libro incluirá la lista total de traducciones de Jane Eyre, más análisis y ensayos surgidos del proceso de investigación. 
translator is a name and often not even that -about 15 per cent of the translators are anonymous, and an unknown number are pseudonymous” (Chau 2020).

A veces, los traductores son solo iniciales. Como León de Sanctis, el traductor de "Nota al pie", el cuento de Rodolfo Walsh en el que la carta que un traductor suicida deja al editor con quien trabajó toda su vida pasa de ser una nota al pie del relato de su muerte a tomarse la página entera del cuento. L.D.S. Así, dice el cuento, aparece el nombre del traductor en su primer libro traducido, en ese y en decenas más, hasta que gana, por tiempo y dedicación, que la editorial le "conceda" poner su nombre completo en algún rincón interior del libro traducido. Para entonces ya es casi demasiado tarde. El traductor, autodidacta, que se enseña inglés a sí mismo con diccionarios y paciencia, cansado del trabajo excesivo y la poca paga se va desilusionando de su trabajo, mientras pasa hambre, frío. En un momento clave del relato debe empeñar su máquina de escribir para poder seguir viviendo. Ya no puede traducir, ha perdido su herramienta y también el deseo, la pasión o el amor, si se quiere, por la traducción. El motor que mueve a su ser amateur se ha roto. Él, que pasó de ser un mecánico de autos a ser un traductor, a pensarse con orgullo como parte de una clase intelectual que finalmente lo desprecia y lo mantiene al margen y en la pobreza, se da cuenta de que ya no puede seguir. Y escribe su carta, donde explica a su editor sus miserias, sin culparlo, aunque detalla cada mal pago, cada trabajo explotador que se le ha encargado, para finalmente suicidarse. Solo entonces, hacia el final de su carta, del relato de su miseria, la nota al pie que es la voz del traductor se toma toda la página, crece en itálicas hasta llenar todo el marco. Sin embargo, este sujeto de los márgenes ha hecho crecer y no desaparecer el borde en el que siempre se ha movido. Ni siquiera su muerte lo saca de ahí porque antes de que se tome el espacio de la página, leemos que tanto el editor como el policía que toma los datos del incidente están listos para seguir en lo suyo, para dar vuelta la página y olvidarse de esa enorme nota al pie. Si bien no todos los traductores tienen finales trágicos, la condición de habitantes de los bordes siempre está presente, de un modo u otro.

Tanto Blackwell como Goldberg, los protagonistas de esta historia, tienen sus propias marginalidades, de género, de raza, de activismo político, pero es precisamente en su lugar marginal que encuentran la libertad para articular su propuesta traductora. Es desde los bordes y desde las condiciones que presenta el panamericanismo que logran pensar un territorio común con las mentes latinoamericanas letradas de su época, una idea que resuena con la noción de cosmopolitismo pensada por el filósofo cínico Diógenes quien creía en la existencia de una ciudad, una comunidad moral definida por la compatibilidad mental y no 
por la vecindad geográfica. ${ }^{9}$ Estos traductores - una amateur, el otro devenido profesional, ambos marginales-, son también cosmopolitas, agentes culturales que trabajan por su idea de mundo desde el borde, tal como lo hacen los escritores latinoamericanos que estudia Mariano Siskind, quienes ven desde su propia orilla -Latinoamérica, lejos del "mundo"- que la modernidad transcurre fuera de su alcance ${ }^{10}$. Así como para ellos el cosmopolitismo puede entenderse como un discurso imaginario que va contra la estructura hegemónica que los deja al margen, Goldberg y Blackwell, desde su paradójico lugar en las orillas del centro geopolítico, conviven en un cosmopolitismo que podemos pensar como un territorio intangible al que intentan incorporar a otros, a los latinoamericanos, y hacerlos habitantes también de una ciudad inmaterial como la que había imaginado Diógenes. Una tarea titánica. Por lo mismo, va aquí el rescate de sus nombres, de su empeño, de algo de su historia traductora.

\section{Nota al pie}

Esto no es una nota al pie, pero sí una nota en medio de estas reflexiones para plantear acá de qué hablamos cuando hablamos de traducción en este libro. Si bien hay aristas, detalles, especificidades que se irán agregando a lo que entiendo por traducción a medida que avanzamos, comienzo aquí adhiriendo a la idea de Lawrence Venuti de entender la traducción desde un modelo hermenéutico, es decir, como una práctica interpretativa que es al mismo tiempo lingüística y cultural y que transforma un texto inicial $-\mathrm{y}$ al mismo tiempo crea un texto otro- de acuerdo a los intereses y particularidades de la cultura que lo recibirá traducido (Venuti 2019: 8, 18). Y sumo a esto las ideas sobre traducción que sostiene el Oxford Comparative Criticism and Translation Research Centre (desde donde se desarrolla Prismatic Jane Eyre ): "Translation is creative, not mechanical; it is a matter of growth as much as, or more than, loss. Translators are writers. Languages are not separate boxes but are rather intermingled areas on the ever-shifting continuum of language variation" (Chau 2020). Allí, entre una definición y otra, entre esos grupos de ideas y declaraciones sobre la traducción, se encuentra el deseo, triangulando, creando tensión entre una lengua y otra, entre culturas, entre lector y traductor.

Si llamo a este apartado "Nota al pie", igual que el cuento de Rodolfo Walsh, es porque es cierto que ese es el lugar, si acaso, que se les suele otorgar

9 Ver Cronin (2006: 7).

10 Ver Siskind (2014). 
a traductoras y traductores, a la traducción en general: el borde, el margen, casi fuera de la página. Este margen del que parecen pender los traductores también ha incluido una lectura de género hecha una y otra vez sobre la traducción y su relación con el resto de los géneros literarios. Como veremos más adelante, históricamente se ha hablado de la traducción feminizándola, otorgándole características con las que también se ha puesto a la mujer, una y otra vez, al margen. Es así como encontramos a la traducción descrita o presentada como la contracara débil, sumisa, sometida, de un texto original al que supuestamente no puede alcanzar, sino solo imitar ${ }^{11}$. En este libro quiero desafiar esa mirada. También quiero criticarla y corregirla y para eso coloco a la traductora, al traductor y a la traducción en el centro de mis páginas y de un trozo de historia. Pero el centro de esta página que presento sigue estando en los bordes porque quiero pensar también ese espacio marginal que ocupan traductores y traducción como un lugar de resistencia e intervención, un aviso, también, de que ahí se está, presente, en el texto que llena la página, ese texto en traducción que es un original nacido de otro modulado en una lengua extranjera que se ha hecho, gracias a la escritura y a la lectura, propio.

\section{¿Por qué este escenario?}

Antes de las guerras por la independencia en América Latina, como ha sido estudiado, ya existía contacto entre un joven Estados Unidos y las que pronto serían las repúblicas independientes del sur, ansiosas de sacudirse de encima el yugo colonial. John T. Reid cuenta que hay evidencia de que la mayoría de los líderes de los procesos de independencia latinoamericanos habían leído la Constitución de los Estados Unidos, la Declaración de Independencia, algunos trabajos de Thomas Paine y algunos de los discursos presidenciales más famosos del país. Reid dice, citando al historiador chileno Barros Arana, que muchos de los criollos habrían tenido copias de estos textos traducidos al francés. Esta última era la lengua extranjera de más prestigio y popularidad entre las mentes ilustradas de Latinoamérica de fines del siglo XVIII, mientras el inglés tenía algunos poquísimos lectores que se encargaban de difundir esas ideas ${ }^{12}$. Dice Reid:

11 Ver capítulo cuatro y la crítica al estilo de traducción de Blackwell.

12 El estatus del francés cambiará más cerca de la Primera Guerra Mundial, cuando el inglés comience a ser visto como la lengua extranjera que presenta más ventajas, como veremos en el capítulo 2. Sobre las lecturas políticas en Latinoamérica alrededor de las guerras de independencia ver: Subercaseaux (2010) y Reid (1977). 
Some of these (texts) were translated in books and periodicals published in South America; others were published in the United States in Spanish translation by Spanish Americans temporarily resident there ... It is probable that some North American merchants and whalers visiting ports in South America carried with them copies of the basic documents and state papers of their homeland (Reid 1977: 10).

Estos tiempos de independencia, de los primeros contactos entre Estados Unidos y lo que sería Latinoamérica, eran tiempos de textos políticos, de traducciones escasas pero vitales, de poco conocimiento de la otra lengua extranjera. Estos primeros contactos estaban atravesados por el deseo de alejarse de la Europa colonizadora, de mantenerla al margen. Un espíritu similar alimentará unas décadas después, en 1823, a la doctrina Monroe. Con ella, Estados Unidos, que ya comenzaba a pensar en la importancia de Centro América para su propio comercio interno costa a costa, instaba a los poderes europeos -especialmente a Gran Bretaña, por ese entonces el país con mayor influencia política y económica en la región- a respetar la independencia de los países latinoamericanos $^{13}$. No sería hasta 1868 que se publicaría en Estados Unidos, en traducción al inglés, un libro escrito en español en una república independiente de Latinoamérica. Los años entre la instauración de la doctrina Monroe y la publicación del Facundo, de Sarmiento, rebautizado en la traducción de Mary Mann como Life in the Argentine Republic in the Days of the Tyrants; or Civilization and Barbarism, fueron años de intervención estadounidense en los países latinoamericanos más cercanos a sus fronteras. Entre 1846 y 1848 se llevó a cabo la guerra contra México que terminó con la anexión estadounidense del 30 por ciento del país vecino y, a partir de la década de 1850, diversas incursiones de filibusteros se abrieron paso en América Central y el Caribe. Estas últimas incluyeron la toma de Nicaragua por William Walker, que tuvo el breve beneplácito de Washington y las varias expediciones a Cuba, todas fracasadas, de Narciso López. Después, a fines de 1860, con Estados Unidos ya delineándose como el futuro poder industrial y económico que sería para fines de siglo, llegó la traducción del Facundo, que todavía tendría el peso del texto político, ya que Mary Mann lo traduciría pensando en ayudar a Sarmiento en su carrera como candidato a la presidencia argentina ${ }^{14}$. Es poco antes, en la década de 1840 para ser más precisos, que las elites criollas comienzan a hablar de Latinoamérica por primera vez, adoptando el nombre acuñado en Francia ${ }^{15}$.

13 Ver Berger (1995).

14 Para más sobre la traducción del Facundo por Mary Mann ver la introducción de la traductora Kathleen Ross en Sarmiento (2004) y el ensayo de Esther Allen en Allen y Bernofsky (2013).

15 Para más sobre el origen del nombre de Latinoamérica y sobre su adopción por las elites criollas latinoamericanas, ver Gobat (2013). 
Toman el nombre no para constituirse como unidad geográfica sino como comunidad cultural, como identidad política, y para diferenciarse de Estados Unidos y marcar un límite a sus ansias expansionistas.

La indiferencia de Estados Unidos para con la cultura de América Latina no vendría a menguar hasta fines del siglo XIX y comienzos del XX, es decir, hasta la formulación del panamericanismo y su promoción de la necesidad de conocer a los "vecinos"16. Por eso mi mirada se posa sobre este marco de tiempo, en este contexto histórico, porque es aquí donde comienza a articularse la relación traductora, tan compleja, esquiva, entre Estados Unidos y Latinoamérica, la misma que irá cambiando, afinándose, a través del tiempo y de marcos de acción delineados por procesos políticos globales o regionales como la Primera y la Segunda Guerras Mundiales, la Política del Buen Vecino -punto cúlmine del panamericanismo-, la Guerra Fría, el neoliberalismo globalizado. Esta es entonces una mirada a las fundaciones, a los comienzos de una relación que, aunque pide cosas específicas a la traducción y a los traductores, ya trae inscritas las preguntas que se siguen haciendo hoy tantos traductores literarios, y no solo los que trabajan entre el inglés y el español. Es decir, en esta escena de traducción específica se busca una respuesta amplia, una forma de conocer y reconocer el trabajo de los traductores literarios en general, y así discernir su valor, hacerlo visible.

Antes de revisar brevemente los contenidos de los capítulos de este libro, quisiera decir que si aquí hablo de Latinoamérica como una entidad medianamente homogénea es porque sigo la mirada que se tenía sobre ella desde Estados Unidos en la época que trato. Para comienzos del siglo XX se pensaba la región en dos bloques: Centro América, México y el Caribe, por un lado y, por otro, América del Sur. Dice Ricardo Salvatore que la primera zona era considerada más inestable política y socialmente, lo que sumado a la cercanía geográfica la hacía más susceptible de intervenciones armadas. El sur, en cambio, era considerado como una tierra de repúblicas más estables, entre las que destacaban los llamados “ABC countries”, Argentina, Brasil y Chile, que presentaban también un constante nivel de progreso económico. Si aquí no considero el caso de la relación traductora de Estados Unidos con la literatura brasileña, de la que Isaac Goldberg fue precursor, es porque baso mi estudio en el trabajo conjunto que hizo este con Blackwell, buscando así en su colaboración en torno al español un terreno común para los dos. Otra razón para no ahondar en este terreno es personal, tiene que ver con mi inte-

16 Durante estos años previos a 1890 en Estados Unidos se produjo una cantidad significativa de libros escritos en español y traducidos al español, muchas veces por exiliados latinoamericanos como el puertorriqueño José María de Hostos o el cubano José Martí. Estos libros se mandaban por barco a las repúblicas del sur. (Ver Allen y Bernofsky 2013). 
rés y conocimiento sobre la circulación de textos entre Estados Unidos y la Latinoamérica que habla español y porque prefiero dejar el vínculo con Brasil en manos más expertas.

En el primer capítulo de este trabajo reviso la historia de un viaje en tren que emprendieron los delegados latinoamericanos invitados a Washington para asistir a la reunión que luego sería conocida como el Primer Congreso Panamericano (octubre de 1888 - abril 1889). A partir del análisis de artículos publicados en su momento por The Chicago Tribune y El Avisador Hispano-Americano leo este viaje de seis mil millas por partes del norte industrial de Estados Unidos y establezco el marco en el que se moverán las prácticas de traducción de Blackwell y Goldberg, es decir el panamericanismo y sus propuestas, las que plantearán demandas específicas a la traducción. Aquí planteo también que el panamericanismo comienza con problemas de traducción, los que van desde el origen mismo del nombre del movimiento hasta ese viaje inaugural en el que no hay traductores ni intérpretes. Además, se exploran las ideas de raza y las jerarquías entre las lenguas y las culturas que entrarán en juego en esta relación traductora que estudiamos.

Entre el primer y el segundo capítulo hago una breve anotación, una pausa, para analizar cómo y por qué el interés por América Latina y todo lo que venga de la región alcanza un punto álgido con el estallido de la Primera Guerra Mundial. Acá observo y exploro cómo cambia la popularidad del español como lengua en el Estados Unidos de la época y cómo comienza la acumulación de conocimiento sobre la región que exigen las ideas detrás del movimiento panamericano.

El segundo capítulo está dedicado a Alice Stone Blackwell, las particularidades de su práctica de traducción y su compleja relación con el panamericanismo, alrededor del cual se movía siempre con una mirada crítica. También aquí recorro la genealogía del término "amateur" y la relación de este con el deseo y la pasión, tal como lo hizo antes Bernard Stiegler. Busco así aliviar al concepto de toda la carga negativa acumulada en su larga confrontación con la idea del "profesional" y destacando su papel como engranaje indispensable en el proceso de circulación de bienes materiales, tal como lo plantea Robert Stebbins. Aquí se presenta una de las propuestas centrales de este trabajo, la idea de que todo traductor literario es un amateur movido por el deseo y el amor y, además y por ser amateur, un sujeto de los bordes. Estas características le permiten moverse alrededor de instituciones académicas, políticas, editoriales- con cierta libertad, la que a su vez le da espacio para resistir, corregir o comentar un orden determinado de cosas, una estructura hegemónica, un desequilibrio de poder entre lenguas y culturas. Blackwell, en este trabajo, representa el epítome del traductor amateur y de la capacidad de resistencia y comentario que encierra su naturaleza. 
En el capítulo 3 se revisa la figura de Isaac Goldberg y su propia práctica de traducción, que emprende desde su formación de profesional de las letras -de las latinoamericanas en particular- de la academia estadounidense de comienzos del siglo XX. Exploro su relación con la literatura y las lenguas latinoamericanas, conformada bajo los preceptos del panamericanismo, especialmente bajo el del mandato de búsqueda de conocimiento, y que, por lo tanto, adquiere un carácter instrumental. La traducción de Goldberg, el contexto que arma en torno a ella, está pensada para explicar América Latina, para conocerla desde la mente y no desde el alma, como propondrá Blackwell. Por lo mismo, la traducción de Goldberg -la hecha con estos propósitos panamericanos- se leerá como más transparente que la traducción de Blackwell, tan marcada por su propio gusto y persona.

En el capítulo 4 vuelvo a la idea del cosmopolitismo como uno de los territorios comunes entre Blackwell y Goldberg, probablemente el que mayor incidencia tuvo en las colaboraciones que emprenden este par de traductores separados por la diferencia generacional, de prácticas y formaciones. Aquí también reviso la diferencia en las estrategias de traducción de uno y otro, analizando una crítica aparecida en la revista Poetry sobre Studies in Spanish-American Literature de Goldberg, que compara los estilos de traducción de Blackwell y Goldberg y, al mismo tiempo, define y alaba la invisibilidad del traductor, que tan bien conceptualizará y criticará Lawrence Venuti. Aquí también cuestiono la feminización de la traducción en relación con otros géneros literarios, la forma en que se le han atribuido rasgos supuestamente femeninos para desvirtuarla y marcarla como un género del margen. También cuestiono la permanente exigencia de fidelidad que se le hace a la traducción y vuelvo, una vez más, sobre el papel del deseo traductor. Cierro este capítulo y este libro con la descripción y análisis de dos momentos fallidos de este escenario de traducción. Primero, el momento en que Blackwell intenta infructuosamente conseguir editorial para su Some Spanish-American Poets, que termina pagando de su bolsillo en 1929 y, luego, los intentos de una Nobel, Gabriela Mistral, antigua y fiel amiga de Blackwell, por ver un libro de su autoría publicado en traducción al inglés. A través de estos dos fracasos exploraré las oscilaciones del interés de Estados Unidos por la literatura latinoamericana y las exigencias de traducciones transparentes y útiles que se desprendía de las ideas del panamericanismo. Veremos cómo estos requisitos panamericanos influyen en la menor presencia de traducciones de poesía en relación a una mayor presencia de novelas y cómo esto mismo hace que trabajos como el de Blackwell se presenten como vehículos de crítica y resistencia a los planteos del movimiento.

No arruina el final de esta historia el contar aquí que los intentos de Blackwell y Goldberg por acercar a Estados Unidos y Latinoamérica a través de la traducción se desmoronan sobre los restos del panamericanismo, que desapareció, fracasado, 
engullido por el reordenamiento geopolítico que siguió al fin de la Segunda Guerra Mundial. Sin embargo, en el intento está la riqueza, ahí es donde se encuentran las complejidades del traductor, del amateur, de las relaciones culturales, intelectuales, que atraviesan lenguas y naciones. Allí también la posibilidad de comenzar a entender la relación traductora entre Estados Unidos y "Latinoamérica”, así, toda, como una región cuya unidad siempre ha flotado utópica, o políticamente construida, sobre nuestra forma de entender la región. Sobre todo, también en este intento se encuentran las posibles respuestas a la pregunta de McDowell que se recoge al comienzo de esta introducción, la misma que tantos se siguen haciendo a pesar del cambio de escenarios, de contextos: ¿Por qué traducimos? 